\title{
A critical analysis of factors for delayed initiation of breast feeding in a district level hospital
}

\author{
M. V. Ramana Rao, Naima Fathima*
}

Department of Obstetrics and Gynecology, SVS Medical College Hospital, Mahabubnagar, Telangana, India

Received: 02 November 2018

Accepted: 16 November 2018

\section{*Correspondence:}

Dr. Naima Fathima,

E-mail: naimaatmbnr@gmail.com

Copyright: () the author(s), publisher and licensee Medip Academy. This is an open-access article distributed under the terms of the Creative Commons Attribution Non-Commercial License, which permits unrestricted non-commercial use, distribution, and reproduction in any medium, provided the original work is properly cited.

\begin{abstract}
Background: Breastfeeding is the cornerstone for child survival. Poor breastfeeding practices contribute to 20 per cent of neonatal deaths and nearly 13 per cent of deaths in children below five years. In south Asia, $40 \%$ of the babies are initiated breastfeeding within one hour despite increase in institutional deliveries, $80 \%$.

Methods: This prospective study was conducted to critically analyse the factors for delayed initiation of breast feeding. A prospective study was carried out among randomly selected postnatal mothers in the postnatal ward of a district teaching hospital. Data was collected by face to face interviews using a pre-validated structured questionnaire. Results: Above $90 \%$ of the women did not know the importance of initiating breast feeding within one hour of delivery as none of them received antenatal counselling. Baby was not given to the mother in $90 \%$ of the cases. $70 \%$ believed that colostrum is not good for the baby. $60 \%$ gave pre-lacteal feeds and $60 \%$ reported pain of surgical site or perineum as the cause for delayed initiation of breast feeding.

Conclusions: UNICEF estimates that if all children receive the benefits of breastfeeding - globally, 8,23,000 child deaths can be averted every year. All health care facilities should adopt Baby Friendly Hospital Initiative's Ten successful steps for breast feeding to initiate early breast feeding within one hour to reduce morbidity and mortality of infants and under five children.
\end{abstract}

Keywords: BFHI, Colostrum, Early breast feeding, Pre-lacteal feeds

\section{INTRODUCTION}

The World Health Organization (WHO) and the United Nations Children's Fund (UNICEF) recommend that children initiate breastfeeding within the first hour of birth and be exclusively breastfed for the first six months of life-meaning no other foods or liquids are provided, including water. From the age of 6 months, children should begin eating safe and adequate complementary foods while continuing to breastfeed for up to two years and beyond. ${ }^{1,2}$ The early initiation of breast feeding, putting newborns to the breast within the first hour of life is crucial to newborn survival and to establishing breast feeding over the long term. Timely initiation of breastfeeding is defined as putting the newborn to breast within one hour of birth. It is one of the ten steps to successful breastfeeding practice and one of the core indicators of assessing appropriate infant and young child feeding practice. ${ }^{1}$

Globally, only $38 \%$ of infants are exclusively breastfed. Suboptimal breastfeeding contributes to 800000 infant deaths. ${ }^{3}$ In 2017 alone, an estimated 78 million newborns had to wait more than one hour to be put to the breast. ${ }^{4}$ This means that only about two in five children (42 per cent), the majority born in low and middle-income countries, were put to the breast within the first hour of life. While this is a slight improvement from 37 per cent in 2005, progress is slow. When breastfeeding is delayed after birth, the consequences can be life-threatening and 
the longer newborns are left waiting, the greater the risk. ${ }^{4}$ An epidemiological evidence of a causal association between early breastfeeding and infection specific mortality in the newborn infants has shown 2.6-fold increased risk of infection specific neonatal mortality with late initiation of breastfeeding (later than day 1). ${ }^{5}$ There are enormous benefits of breast feeding to both the mother and the baby which are well documented. For the baby there is reduced risk of diarrhoea, pneumonia, allergies. For India, breastfeeding can reduce 156,000 child deaths every year, reduce over 3.4 million episodes of respiratory infections and 3.9 million episodes of diarrhoea in young children. A global ecological risk assessment study has found that acute infections, including otitis media, Haemophilus Influenza meningitis and urinary tract infections are less common and less severe in breastfed infants. ${ }^{5}$ Breastfeeding also leads to higher IQ and earning capacity later in life as proved in a recent research showing increasing IQ, educational attainment and monthly income with increasing breastfeeding duration. ${ }^{6}$ Late initiation of breastfeeding, after day one for example, was associated with a 2.6-fold increased risk of infection-specific neonatal mortality. ${ }^{7}$ Early initiation of breast feeding reduces noncommunicable diseases in the long term such as obesity, diabetes.

In South Asia, $40 \%$ of the babies are initiated breastfeeding within one hour. Data of National Family Health Survey-4 (2015-16) for the state of Telangana shows that $91.5 \%$ are institutional deliveries, $91.3 \%$ births are assisted by a health care personnel (doctor, Nurse, Lady health Visitor, auxillary nurse midwife). In contrast to the high institutional deliveries, the early initiation of breast feeding within one hour is $36.5 \%$ only. Children under age 6 months exclusively breast fed are $67 \% .^{8}$ The aim of this study is to study the time of initiation of early breast feeding and to critically analyse the factors for delayed initiation of breast feeding.

\section{METHODS}

A prospective cross-sectional descriptive study was carried out among randomly selected postnatal mothers in the postnatal ward of a district teaching hospital.

\section{Inclusion criteria}

- Mothers delivered vaginally

- Mothers delivered by caesarean section

- Mothers consenting for the interview

- No associated comorbid conditions.

\section{Exclusion criteria}

- Mothers delivered prematurely

- Mothers in ICU or on ventilator

- Mothers whose babies were in NICU

- Refusal for the interview.

\section{Statistical analysis}

Data was collected by face to face interviews using a prevalidated structured questionnaire. The data was entered into an excel and proportions were calculated using SPSS software.

\section{RESULTS}

On analyzing the results, authors found that $78 \%$ of women were $<27$ years of age and a small proportion of women $(5 \%)$ made up of elderly age group 33-37years. There were $42 \%$ of primipara who gave birth first time and multiparous women were $58 \%$. More than $90 \%$ of women were literate. Only $8 \%$ were illiterate, $30 \%$ completed primary education, $40 \%$ secondary education. There were $12 \%$ of graduates and $10 \%$ completed postgraduation. Analysis of house hold income revealed that one fifth of women were from families with less than 5000 INR per month. $32 \%$ of women had income 500010000 INR, 28\% were with income of 10000-15000INR and $20 \%$ of women were with an income of 1500020000INR per month (Table 1).

Table 1: Sociodemographic characteristics.

\begin{tabular}{|l|l|l|}
\hline \multirow{5}{*}{ Sociodemographic variables } & Number \\
\hline \multirow{5}{*}{ Age group in years } & $18-22$ & 38 \\
\hline \multirow{4}{*}{ Parity } & $23-27$ & 40 \\
\cline { 2 - 3 } & $28-32$ & 17 \\
\cline { 2 - 3 } & $33-37$ & 5 \\
\hline \multirow{5}{*}{ Education } & Primipara & 42 \\
\hline \multirow{5}{*}{ Income per month } & Multipara & 58 \\
\hline INR & No education & 8 \\
\hline & Primary education & 30 \\
\hline & Secondary education & 40 \\
\hline & Graduation & 12 \\
\hline & Postgraduation & 10 \\
\hline & $<5000$ & 20 \\
\hline & $5000-10000$ & 32 \\
\hline & $10000-15000$ & 28 \\
\cline { 2 - 3 } & $15000-20000$ & 20 \\
\hline
\end{tabular}

The proportion of women who initiated breast feeding within one hour was $10 \%$ and all these women had vaginal delivery (Table 2).

Table 2: Comparison of mode of delivery with time of initiation of breast feeding.

\begin{tabular}{|lllll|}
$\begin{array}{llll}\text { Mode of } \\
\text { delivery }\end{array}$ & $0-1$ & $1-4$ & $4-8$ & $>8$ \\
haginal & 10 & hours & hours & hours \\
$\begin{array}{l}\text { Vag) } \\
\text { Caesarean }\end{array}$ & $(18.5 \%)$ & $(27.7 \%)$ & 16 & 13 \\
section (46) & 0 & 9 & $10.6 \%)$ & $(24 \%)$ \\
\hline
\end{tabular}

On analysing the reasons for delayed initiation of breast feeding, above $90 \%$ of the women did not know the 
importance of initiating breast feeding within one hour of delivery as none of them received antenatal counselling. Baby was not given to the mother in $90 \%$ of the cases. $70 \%$ believed that colostrum is not good for the baby. $85 \%$ believed that milk will be produced only on 3rd day. (Table 3).

\section{Table 3: Reasons for delayed initiation of breast feeding.}

\begin{tabular}{|l|l|}
\hline Reasons for delayed initiation of BF & Percentage \\
\hline Unawareness & 94 \\
\hline Antenatal counselling given & 0 \\
\hline Baby was not given to the mother & 90 \\
\hline Colostrum is not good to the baby & 70 \\
\hline Pain of surgical site/perineum & 60 \\
\hline Pre-lacteal feeds & 60 \\
\hline Unwillingness of the mother to breastfeed & 4 \\
\hline Nipple problems & 5 \\
\hline Latching issues & 25 \\
\hline Milk will be produced only on $3^{\text {rd }}$ day & 85 \\
\hline Fear of handling newborn baby & 70 \\
\hline
\end{tabular}

Although only $10 \%$ of the women-initiated breast feeding within 1 hour, at the time of discharge $92 \%$ of primiparous women and $98 \%$ of multiparous women were breast feeding (Table 4).

Table 4: Proportion of women breast feeding at the time of discharge.

\begin{tabular}{|ll|}
\hline Parity & Percentage \\
\hline Primipara & 92 \\
\hline Multipara & 98 \\
\hline
\end{tabular}

\section{DISCUSSION}

WHO has released several recommendations on protecting, promoting and supporting breastfeeding in facilities providing maternity and newborn services. Early and uninterrupted skin-to-skin contact between mothers and infants should be facilitated and encouraged as soon as possible after birth. All mothers should be supported to initiate breastfeeding as soon as possible after birth, within the first hour after delivery. These two are important recommendations. ${ }^{9}$ Ironically an increase in institutional deliveries can also negatively influence rates of early initiation if staff members are not appropriately trained and facilities maintain outdated policies and practices that create barriers for breastfeeding-such as separating newborns and mothers without medical justification or routinely providing liquids or foods to the newborn. ${ }^{10}$ Worldwide the rate of institutional deliveries has been increasing over the past decade and three quarters of all deliveries ( 75 per cent) now occurring in health facilities. However, supporting mothers to bring babies to the breast is not always a routine intervention after birth as in present study. In present study, $90 \%$ of the deliveries, baby was not given to the mother. This largely due to traditional practice of taking the baby for wiping, cleaning etc. Then baby is given to a family member or mother if she is moved out of the labour room. Optimally, the baby should be breastfed before any routine procedure such as bathing, weighing, umbilical cord care, administration of eye medications, is performed.

UNICEF's 2016 report, From the First Hour of Life, showed that the presence of a medical doctor, nurse or midwife did not support the early initiation of breastfeeding in many low- and middle-income countries. In South Asia, the early initiation rate in the presence of a skilled provider was much lower, at 34 per cent. This reflects a missed opportunity to support mothers and newborns in initiating breastfeeding immediately after birth. ${ }^{11}$ Authors also found that $70 \%$ of the women had fear of holding the new born baby immediately after delivery. Understandably it is common in primigravidas and some proportion of multiparous women were afraid too, to hold the new born. This was identified as an important barrier to initiate breast feeding. The deliveries were conducted by doctors and there were no birthing partners along with the women. The fear could be alleviated by providing prenatal education and providing adequate support to hold the baby.

No mother received counselling during the antenatal period about initiating breast feeding within one hour after delivery. The importance of counselling has been reiterated in many studies. Mothers who were not counselled about timely initiation of breastfeeding during their antenatal visits were less likely to initiate breastfeeding timely as compared to mothers who were counselled. Though informal counselling is routinely done during antenatal visits, it does not suffice, and it is required to have a formal, dedicated, structured counselling by trained personnel. Lack of these facilities is another barrier for early breast feeding. In a study done in Uttar Pradesh, India, interventions such as peer counselling by mother support groups are shown to have positive effect on infant and young child feeding practices in the community. These interventions have proven to be effective in increasing the initiation of breastfeeding within one hour of birth of baby, exclusive breastfeeding for 6 months, and appropriate start of complementary feeding. ${ }^{12}$ Colostrum is generally perceived as dirty, unhealthy for the baby in this part of the country as shown in present study where $70 \%$ believed it not to be good for the baby. Hence it is discarded, and breastfeeding is delayed during the production of colostrum, waiting until the expected milk comes in. This deprives a newborn of an important source of nutrients and immunologic properties. A large proportion of women $(83 \%)$ believe that milk will be produced only on third day which prompts them to give pre-lacteal feeds or formula milk as the first feed. This belief is prevalent in other parts of India as reported in a study in West Bengal, Inida. In this study, women reported that mother's milk is 'not ready' until two-tothree days postpartum which led to delayed initiation of 
breastfeeding. ${ }^{13}$ In a study, $80 \%$ of primiparous women and $73 \%$ of multiparous women gave formula milk as the first feed to the baby. ${ }^{14}$

Giving pre-lacteal feeds to the new born is a norm and it is largely based on cultural and family practices. Colostrum discarding, and pre-lacteal feeding have been proved to delay the initiation of breast feeding also it adversely affects the long-term continuation of breast feeding. Efforts to avoid supplementing newborns with liquids or foods other than breast milk are crucial to successful breastfeeding outcomes. In present study, on analysing the type of delivery, $58.6 \%$ of the babies born by Caesarean section were breast feed later than 8 hours compared to $24 \%$ of babies delivered vaginally. Half of the babies $(46.2 \%)$ born by vaginal delivery were breast fed within 4 hours after birth compared to $19.5 \%$ born by Caesarean section. Several studies show that surgical deliveries can reduce the likelihood of immediate skin-toskin contact and the early initiation of breastfeeding. ${ }^{15,16}$ Almost all newborns delivered by Caesarean section can be put to the breast within the first hour after birth if adequate support is provided. However, in practice, it is easier said than done as women who deliver by Caesarean section often face important challenges in initiating breastfeeding, such as managing the effects of anaesthesia, recovering from surgery and finding help to hold the baby safely. Pain of surgical site and fatigue are other barriers for early initiation of breast feeding. In present study $60 \%$ of the women reported pain as one of the reasons for the delay in feeding. Mothers who have undergone Caesarean section need extra help with breastfeeding. Otherwise, these mothers on average initiate breastfeeding much later and terminate breastfeeding sooner. Incorrect latching leads to difficulties in initiation and continuation of breast feeding and was reported in $25 \%$ of the women in present study.

Birth by caesarean section, discarding of colostrum, unmarried mothers, exposure to infant formula advertisement and no house ownership were independent factors associated with delay in initiation of breastfeeding in a study done in South Sudan. ${ }^{17}$ A study done on determinants of poor feeding practices in India has indicated that the rates of timely initiation of breastfeeding were higher among women who were better educated, were working, had more antenatal clinic visits and were exposed to the radio. The rates were lower in women who were delivered by Caesarean section. ${ }^{18}$ Reported barriers according to a review of factors and barriers for early initiation of breast feeding in South Asia, are traditional feeding practices, priests' advice, pre-lacteal feeding and discarding colostrum, mother-in-law's opinion on new born care, lack of information, low access to media and health services, misperception, support and milk insufficiency, no involvement of mothers in decision making. ${ }^{15}$ Critical evaluation of present practices has revealed that, the design of the labour bed is not conducive for the pregnant woman to recline/ sit to hold the new born baby to breast feed in the labour room. It is not a usual practice to allow birthing partner or a family member in to the labour room. Even though all deliveries are conducted by resident doctors, baby was not placed skin to skin contact with mother. It may be desirable to involve a family member or any other close relative of the woman to help her to initiate breast feeding when there is scarcity of trained personnel or sister. Other practices such as monitoring the mother and repairing of Episiotomy are given priority than early breast feeding. Regular counselling sessions involving the family members will have more positive impact considering the influence of the immediate family on decisions regarding infant feeding. Important barriers such as taking the baby away from the mother, keeping the mother for too long in the labour room and not allowing family member or partner into the labour room have to be overcome to enable the mother to have skin to skin contact with the baby as well as initiate breast feeding. There is no trained person to educate and demonstrate the positioning and correct latching to the mothers who have latching issues.

Limitations of this study were authors did not correlate the income, education with the time of initiation of breast feeding. Study is not extended into the community to know whether these women were practicing exclusive breast feeding. Though the percentage of women initiating breast feeding within one hour is dismal, it is encouraging to note that more than $90 \%$ of the women were breast feeding at the time of discharge from the hospital. However, $90 \%$ of the babies are missing out on the benefits of early breast feeding within one hour.

India ranks 56 in the percentages of initiation of early breast feeding. According to the WHO rating on early initiation of breastfeeding; 0-29\% is considered poor, 30$49 \%$ as fair, $50-89 \%$ as good and $90-100 \%$ as very good. ${ }^{19}$ According to this rating, present rating is poor with just $10 \%$ of babies breast fed within one hour after delivery. This necessitates us to adopt the policies and recommendations by WHO and UNICEF. It is time to adopt Baby Friendly Hospital Initiative's ten steps for successful breast feeding. A systematic review of the Baby-friendly Hospital Initiative (BFHI) in 19 countries showed that facilities' adherence to the BFHI's Ten Steps to Successful Breastfeeding can increase breastfeeding rates, including the early initiation of breastfeeding. ${ }^{20}$ Steps need to be taken to ensure that counselling and education is provided during antenatal care. Adequate support during delivery and throughout the postnatal stay should be provided. Though only $10 \%$ of the womeninitiated breast feeding within one hour of delivery, at the time of discharge more than $90 \%$ of the women were breast feeding. These women need support in the community to ensure exclusive breast feeding in the first 6 months. The goal of WHO is by 2025 , increase to at least $50 \%$ the rate of exclusive breastfeeding in the first six months. ${ }^{3}$ Effective community-based strategies to support exclusive breastfeeding counselling for pregnant 
and lactating women by peer-to-peer and group counselling are paramount to achieve this goal.

\section{CONCLUSION}

The increase in institutional deliveries has not always translated into improvements in the rate of early initiation of breastfeeding. The low global rates of early initiation of breastfeeding despite increased institutional deliveries are evidence of a massive missed opportunity worldwide and there is great potential for skilled birth attendants to support mothers in initiating breastfeeding immediately after birth. Provision of counselling on breastfeeding during the antenatal period, at the time of delivery, other health contacts, and during home visits, are essential for promoting, supporting and protecting breastfeeding. Outdated practices where mothers and babies are separated immediately after birth should be abolished. All health care facilities should adopt Baby Friendly Hospital Initiative's Ten successful steps for breast feeding to initiate early breast feeding within one hour to reduce morbidity and mortality of infants and under five children.

\section{Funding: No funding sources \\ Conflict of interest: None declared \\ Ethical approval: Not required}

\section{REFERENCES}

1. World Health Organization, Guideline: protecting, promoting and supporting breastfeeding in facilities providing maternal and newborn services, WHO, Geneva 2017.

2. World Health Organization, United Nations Children's Fund. Global strategy for infant and young child feeding., WHO, Geneva, 2003.

3. WHO global targets 2025 to improve maternal, infant and young child nutrition. Available at: https://www.who.int/nutrition/global-target-2025/en/.

4. UNICEF, WHO. Capture the Moment-Early initiation of breastfeeding: The best start for every newborn. New York: UNICEF; 2018

5. Lauer JA, Betrán AP, Barros AJ, de Onís M. Deaths and years of life lost due to suboptimal breast-feeding among children in the developing world: a global ecological risk assessment. Public Health Nutr. 2006;9:673-85.

6. Victora CG, Horta BL, Loret de Mola C, Quevedo L, Pinheiro RT, Gigante DP, et al. Association between breastfeeding and intelligence, educational attainment, and income at 30 years of age: a prospective birth cohort study from Brazil. Lancet Glob Health. 2015;3(4):e199-205.

7. Edmond KM, Kirkwood BR, Amenga-Etego S, OwusuAgyei S, Hurt LS. Effect of early infant feeding practices on infection-specific neonatal mortality: an investigation of the causal links with observational data from rural Ghana. Am J Clin Nutr. 2007;86:1126-31.
8. National Family health Survey 4 (2015-16), Government of India, Ministry of health and Family Welfare. Available at: http://rchiips.org/nfhs/pdf/NFHS4/TG_FactSheet.pdf.

9. Protecting, promoting and supporting breastfeeding in facilities providing maternity and newborn services. Available at: http://www.who.int/nutrition/publications/guidelines/br eastfeeding-facilities-maternity-newbornsummary.pdf?ua $=1$.

10. World Health Organization, Standards for improving quality of maternal and newborn care in health facilities, WHO, Geneva, 2016. Available at: http://apps.who.int/iris/bitstream/10665/249155/1/9789 241511216-eng.pdf?ua=1, accessed17 July 2018.

11. United Nations Children's Fund, From the first hour of life, UNICEF, New York, 2016.

12. Kushwaha KP, Sankar J, Sankar MJ, Gupta A, Dadhich JP, Gupta YP, et al. Effect of peer counselling by mother support groups on infant and young child feeding practices: the Lalitpur experience. PloS One. 2014;9(11):e109181.

13. Bandyopadhyay M. Impact of ritual pollution on lactation and breastfeeding practices in rural West Bengal, India. Int Breastfeeding J. 2009;4(1):2.

14. Pandya A, Chavada M, Jain R, Verma PB. Determinants for delayed initiation of breastfeeding: A hospital based comparative study between primiparous and multiparous mothers. J Med Res. 2015;1(2):49-54.

15. Sharma IK, Byrne A. Early initiation of breastfeeding: a systematic literature review of factors and barriers in South Asia. Int Breastfeeding J. 2016;11(1):17.

16. Rowe-Murray HJ, Fisher JR. Baby friendly hospital practices: cesarean section is a persistent barrier to early initiation of breastfeeding. Birth. 2002;29(2):124-31.

17. Tongun JB, Sebit MB, Mukunya D, Ndeezi G, Nankabirwa V, Tylleskar T, et al. Factors associated with delayed initiation of breastfeeding: a crosssectional study in South Sudan. Int Breastfeeding J. 2018;13(1):28.

18. Patel A, Badhoniya N, Khadse S, Senarath U, Agho KE, Dibley MJ. South Asia infant feeding research network. Infant and young child feeding indicators and determinants of poor feeding practices in India: secondary data analysis of National Family Health Survey 2005-06. Food Nutr Bull. 2010;31(2):314-33.

19. World Health Organization. Indicators for assessing infant and young child feeding practices. Geneva: World Health Organization; 2010. Available at: http://www.who.int/nutrition/publications/infantfeeding /9789241599290/en/.

20. Pérez-Escamilla R, Martinez JL, Segura-Pérez S. Impact of the Baby-friendly Hospital Initiative on breastfeeding and child health outcomes: a systematic review. Mat Child Nutr. 2016;12(3):402-17.

Cite this article as: Rao MVR, Fathima N. A critical analysis of factors for delayed initiation of breast feeding in a district level hospital. Int J Reprod Contracept Obstet Gynecol 2018;7:4840-4. 